\title{
Open question: Water structures and their implications for the biological cell
}

\author{
Frank Mayer* \\ Institute for Microbiology and Genetics, Georg August University Goettingen, Germany
}

Water is the indispensable element of life. Many efforts have been made to discover its properties beyond those observed in our daily life. An example is the experimental finding of two Russian scientists: they discovered water with very strange properties (lower freezing point of $-40^{\circ}$ or less, boiling point at $150^{\circ}$, a density significantly higher than usual bulk water). In the journal Science, a paper was published that described similarities of polywater with sweat [1]. The Russian scientists had obtained this water by condensation or repeated passage through narrow quartz capillaries. After years of scientific furor, it finally turned out that this mysterious fluid, after the experiments were repeated with thoroughly cleaned glassware, lost its anomalous properties: they were caused by contaminating impurities.

This example is described to illustrate the fact that even today, any experiments related to special properties of water encounter an enormous distrust. Scientists who dare to publish related findings can have major difficulties in fund raising.

Nevertheless, in the meantime a number of scientists did experimental work in the field of water structure, and many of their results are worth to be noted.

One of the pioneers in the field was Philippa Wiggins with her paper on enzymes and two-state water [2], a summary of her previous experimental work. Based on her earlier findings on two states of water (low density water, high density water, and "interfacial water", i.e., water close to surfaces), experiments dealing with activities of microorganisms and "membrane-bound" enzymes in water-restricted environments [3] and with enzymes (hydrogenases) in water-in-oil microemulsions [4] were performed. It turned out that the specific activities of membrane-bound enzymes are significantly higher in restricted environments such as reversed micelles (microdroplets of water, surrounded by a layer of surfactant molecules, dispersed in an organic solvent) than in conventional buffer/bulk water systems. Within reversed micelles with diameters lower than $20 \mathrm{~nm}$, electron microscopic investigations revealed that the enzyme complexes trapped in the reversed micelle were usually positioned right in the center of the reversed micelle. There, according to Philippa Wiggins the water has the state of lower density, whereas high density water-to balance out the overall density of the total water content inside the reversed micelle-is located as a lining at the hydrophilic inner face of the "wall" of the reversed micelle. As mentioned above, specific enzyme activities are much higher in reversed micelles of appropriate dimension compared to specific activities of "membrane-bound"enzymes located in immediate vicinity of membrane surfaces. A test system was designed for confirmation of this principle as follows: liposomes with a "membrane-bound" enzyme attached to the outside surface of the liposome membrane were used as a control for determination of specific activity of the enzyme. According to the finding in experiments with reversed micelles (s.above) one could expect low specific enzyme activity. The test proper was performed with the same enzyme, but now positioned, by binding at the top of a Streptavidin stalk of various lengths, anchored in the liposome membrane, at various distances from the (hydrophilic) liposome membrane. Actually, the specific enzyme activity did depend on the length of the stalk; a length of the stalk not less than $5 \mathrm{~nm}$ showed high specific enzyme activity. Enzyme positions closer to the surface of the liposome membrane gave lower values [5]. These results can be assumed to best represent the situation within the cell regarding "membrane-bound" enzymes: the catalytic centers of these enzymes are not positioned in immediate contact with the membrane surface (in the high-density water area) but several $\mathrm{nm}$ away from the membrane surface (in the low-density water area). These data are valid for "membrane-bound" enzymes, not for enzymes in the cytosol of the cell. "Membrane-bound" enzymes need close neighbourhood to cooperating membrane-integrated reaction partners However, in this context the functions of the stalks, besides placing the catalytic centers of the enzymes in low-density water, should be investigated. Additional questions may arise: can these facts of architecture of biological cells indicate that specific water structures may have had an influence on cell architecture during evolution? Could the mode of placement of "membrane-bound" enzymes in the "best" water structure, i.e., attachment of the enzyme at the top of a stalk, have been a selective advantage during evolution? Could this mean that the kind of structural organization observed in today's biological cells be the consequences of water properties? The field is open for speculations. Below, in the section on "Exclusion Zones" and "Fourth phase of water", high density water, low density water and interfacial water are again described, but the respective water moieties have other names.

A few years ago, Gerald H. Pollack, a scientist working with his group in Seattle on topics related to water, published a book with the title "The Fourth Phase of Water-Solid, Liquid, and Vapor" [6]. This book brought revolutionary ideas in the field of water structure. It describes "Exclusion Zones", i.e., zones of water that are formed spontaneously,

Correspondence to: Frank Mayer, Seerosenweg 1a, D-26160 Bad Zwischenahn Germany, Tel : +49 4403602 1997; E-mail: fmayer12@gmx.de

Key words: bulk water, polywater, structured water, enzyme activities in water restricted environments, reversed micelles, liposomes, low density water, high density water, interfacial water, evolutionary aspects, fourth phase of water, "Exclusion Zones" EZ, liquid crystalline water

Received: June 10, 2017; Accepted: July 03, 2017; Published: July 06, 2017 
located close to hydrophilic surfaces; they do not allow any solutes and dissolved materials (salt and other ions, small particulate material, molecules in size down to small molecular complexes) to penetrate these zones of water located close to hydrophilic surfaces. Examples in biological cells are surfaces of biological membranes. In addition, Pollack discusses the composition and organization of the water in these zones and proposes that this water is "liquid crystalline water" with the formula $\mathrm{H}_{3} \mathrm{O}_{2}$. Critics who wrote reviews of the book blamed Pollack to commit infringement of the Octet Rule (oxygen is divalent, the critics feel that, in the formula, oxygen would need to be three valent). However, exceptions from this rule can exist, depending on specific conditions [7]. X-ray crystallographic data on the assumed crystalline character of water in the exclusion zones are, so far, missing. However, in a book written by Mae Wan Ho with the title "The Rainbow and the Worm-The Physics of Organisms" it is shown that crystalline matter in a biological sample, in her case a worm, does exist in living biological cells. This was achieved with a specifically equipped light microscope; a pattern of brilliant colours was visible all over the image of the worm, indicating the presence of crystalline matter, interpreted as liquid crystalline water [8]. The water in the exclusion zones may be, according to P. Wiggins' nomenclature [2], dense water, and the water inside the cell may be, also according to P. Wiggins, less dense water. It is obvious that further investigations into the correct formula of the water in exclusion zones, on the supposed liquid crystalline character of this water, and on the reason and the mechanism of the phenomenon "exclusion" are needed.

Data have been collected regarding the mode of structural enzyme organization in biological cells possibly containing exclusion zones [9, and s. above text, keyword: stalks). It was speculated that lumps of wet plant polysaccharides might contain a lot of liquid crystalline water. After all, the total surface of the material in the lump has hydrophilic properties [10,11].

As expected, much skepticism is evident as far as the existence of liquid crystalline water with the formula $\mathrm{H}_{3} \mathrm{O}_{2}$ and a multitude of novel and surprising properties of liquid crystalline water are concerned [6)] The situation might get even worse because a variety of companies now use the findings on liquid crystalline water for unjustified treatment for better human health; the advert claims these products not only to be good for well-being but also to be good value for money. Example: liquid crystalline water might act as a battery energized by light [6], and collected and stored energy could then be used to support physical and mental human health; products are offered that enable the customer to treat himself. Situations like this caused the FDA(US Food and Drug Administration) to send warnings to companies of this kind.

In summary: Brian Josephson, Nobel Laureate, Cambridge University, did state in a review of Gerald H. Pollacks book "The Fourth Phase of Water-Solid, Liquid, and Vapor" published on the Homepage of Ebner and Sons, Publishers (a company founded by Gerald H. Pollack for publication of his numerous books): "Dr. Pollack is one of the pioneers of this field, and his discoveries can be expected to have important implications".

\section{References}

1. Rousseau DL(1971) Polywater and sweat: similarities between their infrared spectra Science 171: 170-172.[Crossref]

2. Wiggins P (2002) Enzymes and two-state water. J Biol Physics and Chemistry 2: 25-37

3. Hoppert M, Mlejnek K, Seiffert B, Mayer F (1997) Activities of microorganisms and enzymes in water-restricted environments: biological activities in aqueous compartments at micrometer-scale. SPIE The International Society for Optical Engineering, Proceedings Series 3111: 501-509.

4. Hoppert M, Mlejnek,K, Mayer,F(2001) Hydrogenases in water-in-oil microemulsions. In: Hydrogen as a Fuel. Cammack R, Frey M, Robson R (Eds,.) Taylor \& Francis Publishers London, pp.198-200.

5. Wichmann C, Naumann PT, Spangenberg O, Mayer F, Hoppert M, et al. (2003) Liposomes for microcompartmentation of enzymes and their influence on catalytic activity. Biochem Biophys Res Comm 310: 1104-1110.[Crossref]

6. Pollack GH (2013) The Fourth Phase of Water -Solid, Liquid, and Vapor. Ebner and Sons Publishers, Seattle, USA.

7. Gillespie RJ, Silvi B (2002) The octet rule and hypervalence: two misunderstood concepts. Coord Chem Rev 233-234: 53-62.

8. Mae Wan Ho (2008) The Rainbow and the Worm-The Physics of Organisms. World Scientific Publishing. Singapore.

9. Mayer F (2015) "Exclusion Zones" in biological cells? Swift J of Medicine and Medical Sciences 1: 18-22.

10. Mayer F (2015) Plant polysaccharide gels-Some properties and applications in irrigation systems, horticulture and soil protection. Swift J Agricult Res 1: 47-48.

11. Mayer F (2015) "Fourth phase water"-“Liquid crystalline water" in plant polysaccharide gels? Swift J of Pure and Applied Chemistry 1: 1-2.

Copyright: (C2017 Mayer F. This is an open-access article distributed under the terms of the Creative Commons Attribution License, which permits unrestricted use, distribution, and reproduction in any medium, provided the original author and source are credited. 